\title{
Long-term Breastfeeding in the Prevention of Allergic Rhinitis: Allergic Rhinitis Cohort Study for Kids (ARCO-Kids Study)
}

\author{
Doo Hee Han ${ }^{1, \star}$ (1) $\cdot$ Jae-Min Shin ${ }^{2, \star} \cdot$ Seokyung $\mathrm{An}^{3,4,5} \cdot$ Jong Seung Kim ${ }^{6} \cdot$ Dong-Young Kim ${ }^{1} \cdot$ Sungji Moon ${ }^{3,4,5}$ \\ Jung-Soo $\mathrm{Kim}^{7} \cdot$ Joong Saeng $\mathrm{Cho}^{8} \cdot \mathrm{Si}$ Whan $\mathrm{Kim}^{9} \cdot$ Young Hyo Kim${ }^{10}$ • Hwan-Jung Roh ${ }^{11} \cdot$ Woo Sub Shim ${ }^{12}$ \\ Ki-Sang Rha ${ }^{13} \cdot$ Sang-Wook Kim ${ }^{14,15} \cdot$ Seung-Sin Lee ${ }^{16} \cdot$ Dae Woo Kim $^{17} \cdot$ Kyu-Sup Cho ${ }^{11} \cdot$ Hyo Jin Yim ${ }^{1}$
} Sue K. Park ${ }^{3,4,5}$ (i) $\cdot$ Chae-Seo Rhee ${ }^{1,18,19,20}$ (i)

\begin{abstract}
${ }^{1}$ Department of Otorhinolaryngology, Seoul National University College of Medicine, Seoul; ${ }^{2}$ Department of Otorhinolaryngology, Soonchunhyang University College of Medicine, Seoul; ${ }^{3}$ Department of Preventive Medicine, Seoul National University College of Medicine, Seoul; ${ }^{4}$ Department of Biomedical Science, Seoul National University Graduate School, Seoul, ${ }^{5}$ Cancer Research Institute, Seoul National University, Seoul; ${ }^{6}$ Department of Otolaryngology-Head and Neck Surgery, Chonbuk National University Medical School, Jeonju; ${ }^{7}$ Department of Otorhinolaryngology-Head and Neck Surgery, School of Medicine, Kyungpook National University, Daegu; ${ }^{8}$ Department of Otolaryngology-Head and Neck Surgery, Kyung Hee University School of Medicine, Seoul; ${ }^{9}$ Department of Otolaryngology-Head and Neck Surgery, Hallym University Sacred Heart Hospital, Hallym University College of Medicine, Anyang; ${ }^{10}$ Department of Otorhinolaryngology-Head and Neck Surgery, Inha University College of Medicine, Incheon; ${ }^{11}$ Department of Otorhinolaryngology-Head and Neck Surgery, Pusan National University School of Medicine, Busan; ${ }^{12}$ Department of Otorhinolaryngology-Head and Neck Surgery, Chungbuk National University College of Medicine, Cheongju, ${ }^{13}$ Department of Otolaryngology-Head and Neck Surgery, Chungnam National University School of Medicine, Daejeon; ${ }^{14}$ Department of Otorhinolaryngology, Gyeongsang National University Hospital, Jinju; ${ }^{15}$ Institute of Health Sciences, Gyeongsang National University, Jinju; ${ }^{16}$ Department of Otolaryngology-Head and Neck Surgery, Ewha Womans University School of Medicine, Seoul; ${ }^{17}$ Department of Otorhinolaryngology-Head and Neck Surgery, SMG-SNU Boramae Medical Center, Seoul; ${ }^{18}$ Graduate School of Immunology, Seoul National University College of Medicine, Seoul; ${ }^{19}$ Institute of Allergy and Clinical Immunology, Seoul National University Biomedical Research Center, Seoul; ${ }^{20}$ Sensory Organ Research Institute, Seoul National University Biomedical Research Center, Seoul, Korea
\end{abstract}

Objectives. There is a great deal of interest in the possibility that environmental factors may influence the risk of developing allergic rhinitis (AR) in early life. We investigated the simultaneous effects of mode of delivery and duration of breastfeeding on the development of AR in children.

Methods. Data from 1,374 children participating in the Allergic Rhinitis Cohort Study for kids (ARCO-kids study) was analyzed. All subjects were divided into AR or non-allergic rhinitis (NAR) groups. Data on environmental factors, mode of delivery and duration of breastfeeding were collected using a questionnaire.

Results. Compared with short-term breastfeeding ( $<6$ months), long-term breastfeeding ( $\geq 12$ months) was significantly associated with a lower prevalence of AR (adjusted odds ratio [aOR], $0.54 ; 95 \%$ confidence interval [CI], 0.34 to 0.88). Children in the AR group also had a higher cesarean delivery rate than those in the NAR group ( $39.1 \%$ vs. $32.8 \%, P=0.05)$. Regarding the combined effects of mode of delivery and duration of breastfeeding, long-term breastfeeding with a vaginal delivery strongly suppressed the development of AR, compared to short-term breastfeeding with a cesarean delivery (aOR, $0.47 ; 95 \% \mathrm{CI}, 0.30$ to 0.73 ).

Conclusion. Long-term breastfeeding ( $\geq 12$ months) and a vaginal delivery are associated with a lower risk of developing childhood AR.

Keywords. Rhinitis, Allergic; Breast Feeding; Environment; Delivery, Obstetric; Cesarean Section

- Received November 30, 2018
Revised February 26, 2019

Accepted March 11, 2019

- Corresponding author: Chae-Seo Rhee

Department of Otorhinolaryngology, Seoul National University Hospital,

101 Daehak-ro, Jongno-gu, Seoul 03080, Korea

Tel: +82-2-2072-3991, Fax: +82-2-766-2447, E-mail: csrhee@snu.ac.kr

\footnotetext{
- Co-Corresponding author: Sue K. Park

Department of Preventive Medicine, Seoul National University College of Medicine, 101 Daehak-ro, Jongno-gu, Seoul 03080, Korea

Tel: +82-2-740-8338, Fax: +82-2-747-4830, E-mail: suepark@snu.ac.kr

*These authors contributed equally to this work.
}

Copyright $\odot 2019$ by Korean Society of Otorhinolaryngology-Head and Neck Surgery.

This is an open-access article distributed under the terms of the Creative Commons Attribution Non-Commercial License (http://creativecommons.org/licenses/by-nc/4.0) which permits unrestricted non-commercial use, distribution, and reproduction in any medium, provided the original work is properly cited. 


\section{INTRODUCTION}

Allergic rhinitis (AR) is a global health issue that represents a significant healthcare burden with serious adverse effects on quality of life. Moreover, several longitudinal studies have shown that AR often precedes the development of asthma, suggesting that it might be a risk factor for asthma, especially in school-aged children [1,2].

Although the development of any allergic disease depends on many variables and reflects the interaction between genetic and environmental factors, the nature of these associations remains unclear [3]. As the ability to modify genetic influences is still limited, attention has focused on the environmental factors that might be amenable to intervention. To this end, many studies have aimed to identify the factors affecting the clinical expression of allergic diseases. These environmental factors can be divided into three categories; maternal, prenatal and postnatal, according to data related to exposure during pregnancy or the subsequent birth, and they may modulate fetal immunological development, and thereby be associated with the development of allergic diseases $[4,5]$. Among the environmental factors, the impacts of breastfeeding and mode of delivery (MOD) on the development of allergies have long been investigated.

An Australian study found that exclusive breastfeeding for $\geq 4$ months had a protective effect against asthma, independent of the maternal allergic status [6], and a recent meta-analysis showed a $20 \%$ increase in the subsequent risk of asthma in children who had been delivered by cesarean section [7]. However, the effect of these environmental factors on allergic disease remains controversial [8-11]. Most previous studies that investigated the effect of the duration of breastfeeding on allergic disease focused on early exclusive breastfeeding [12-15], whereas we investigated the effects of long- or short-term breastfeeding simultaneously with the impacts of MOD and duration of breastfeeding on the development of allergic disease in Asian children. We addressed these issues by analyzing data on AR and environmental factors, collected from children in a large cohort study. The Allergic Rhinitis Cohort Study for kids (ARCO-kids study) is a prospective, hospital-based cohort study of children

\section{H I G H L L I}

- Data from 1,374 children participating in the Allergic Rhinitis Cohort Study for kids (ARCO-kids study) was analyzed.

- Long-term breastfeeding was significantly associated with a lower prevalence of allergic rhinitis.

- Children in the allergic rhinitis group also had a higher cesarean delivery rate than those in the non-allergic rhinitis group.

- Long-term breastfeeding ( $\geq 12$ months) and a vaginal delivery are associated with a lower risk of developing childhood allergic rhinitis. with allergic or non-allergic rhinitis (NAR) in Korea. This study enrolled pediatric patients with rhinitis from 14 centers located in the six provinces of South Korea, and has been recruiting participants since February 2009.

The present study was designed as a cross-sectional study to ascertain the possible perinatal environmental factors that influence the risk of AR in childhood using the initial data from ARCO-kids study.

\section{MATERIALS AND METHODS}

\section{Study design}

The study subjects were enrolled in ARCO-kids study between February 2009 and May 2011. A total of 1,374 children with rhinitis, aged 4-12 years, were recruited from 14 centers located in six provinces of South Korea during this period (Fig. 1). All enrolled children received a physical examination and a skin prick test for a panel of 13 aeroallergens.

The parents of all the participating children provided informed consent, after which they completed an extensive questionnaire on the social and environmental factors during the prenatal and postnatal period, and then a standardized questionnaire about their child's quality of life. A further two questionnaires about the symptoms and complications related to AR were completed at 6 -month intervals thereafter. The data from the initial extensive questionnaire was analyzed to investigate the association between environmental factors and the development of AR. This questionnaire included questions on age, sex, maternal age at marriage, maternal age at birth, maternal weight gain during pregnancy, birth weight, gestational age at birth, MOD, duration of breastfeeding, number of siblings, parental smoking, history of allergy, and living area. The Institutional Review Board of each hospital approved the study protocol and the informed consent statements.

\section{Clinical definitions}

Subjects with rhinitis were divided into an AR group (those with current atopy), or a NAR group (those without atopy), according to their reactions to the skin prick test. Duration of breastfeeding was divided into the following three categories, according to the age at which breastfeeding stopped; $<6$ months (short-term breastfeeding), 6-11 months, and $\geq 12$ months (long-term breastfeeding). MOD was categorized as either vaginal or cesarean. All vaginal deliveries, including vacuum extraction or forceps were combined into a single category, and all types of cesarean deliveries (elective and emergency) were also regarded as a single category. The number of siblings was also classified as follows: 0 sibling, 1 sibling, and $\geq 2$ siblings.

\section{Laboratory methods}

Skin prick tests to common allergens in Korea were performed 


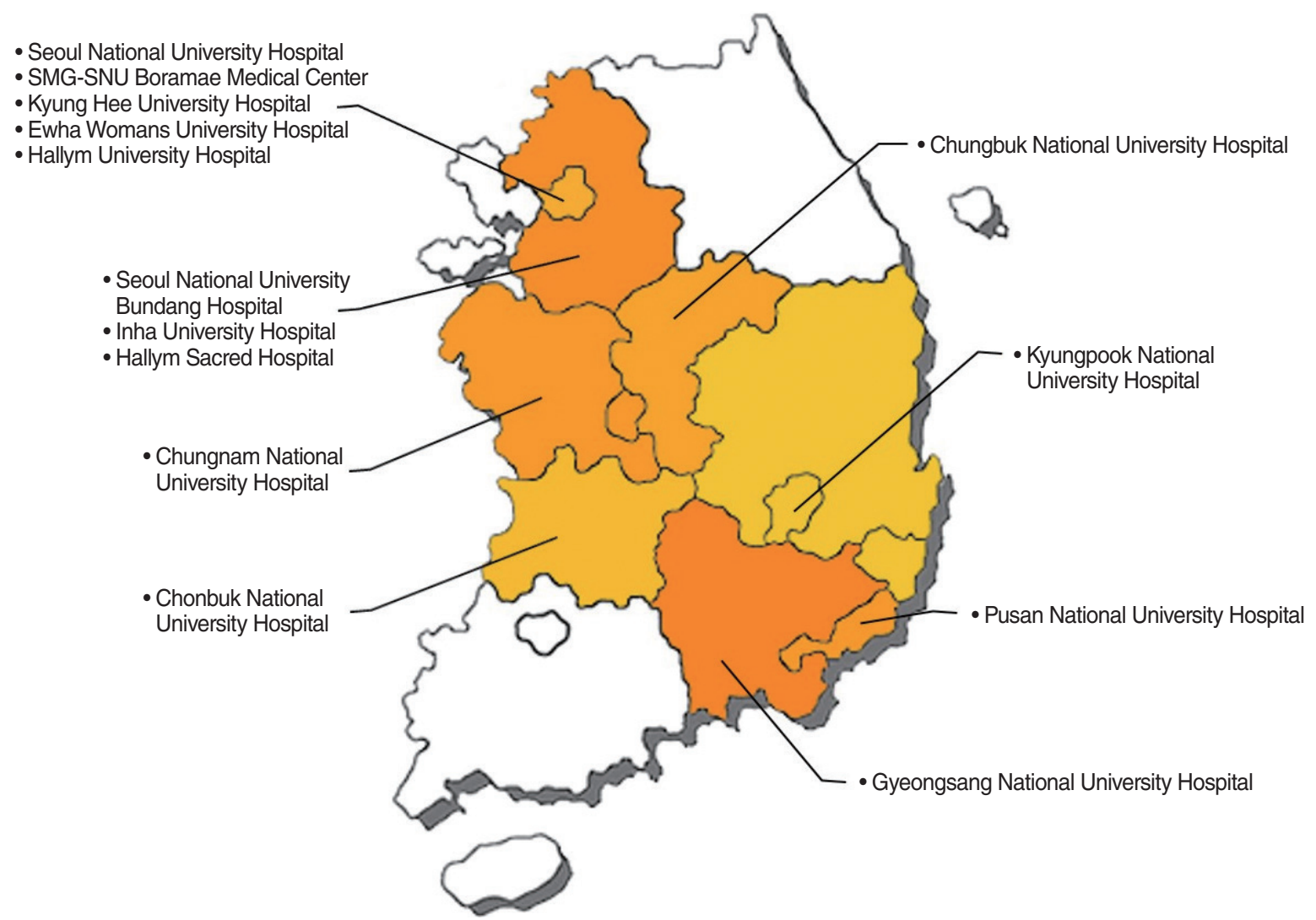

Fig. 1. The 14 participating centers located in the six provinces of Korea, from the Allergic Rhinitis Cohort Study for kids (ARCO-kids).

using standardized extracts (Allergopharma, Reinbek, Germany) of house dust mites (Dermatophagoides pteronyssinus and Dermatophagoides farinae), animal dander (cat and dog epithelia), pollens (grass mix, tree mix I, tree mix II, mugwort, ragweed, and oak), molds (Alternaria alternata and Aspergillus fumigatus) and cockroaches (Blattella germanica), which could detect more than $98 \%$ of allergen-sensitized patients in Korea [16]. A mean wheal diameter $\geq 3 \mathrm{~mm}$ was regarded as positive. Individuals with at least one positive skin test result were considered to have atopy.

\section{Data analysis}

The following parameters in the AR and NAR groups were compared; children's age and sex, maternal age at marriage, maternal age at birth, maternal weight gain during pregnancy, birth weight of infants, gestational age at birth, MOD (vaginal vs. cesarean), duration of breastfeeding, number of siblings, parental smoking, history of allergy, and living area.

Categorical and continuous predictor variables were evaluated for association with AR by the Pearson chi-square test and $t$ tests, respectively. Relationships were analyzed using logistic regression analysis. A final logistic regression model was developed using predictor variables that were identified with AR by means of the aforementioned methods. Factors with a $P$-value
$<0.15$ was chosen for inclusion in a multiple logistic regression model. Results are presented as unadjusted odds ratio (OR) and adjusted odds ratio (aOR) with the corresponding $95 \%$ confidence interval $(\mathrm{CI})$. All potential confounders were simultaneously included in the logistic regression model to adjust the analyses. All statistical analyses were performed using the SAS ver. 9.1 (SAS Institute Inc., Cary, NC, USA).

\section{RESULTS}

Of the 1,374 participants in this study, 433 (32\%) were female, and 941 (68\%) were male. Those suffering with AR comprised $77 \%$, with $23 \%$ having NAR. Table 1 details the risk factors for AR among the 1,374 subjects, as well as their characteristics. Children belonging to the AR group had a higher cesarean delivery rate compared with those in the NAR group $(39.1 \%$ vs. $32.8 \%, P=0.051)$. The AR group also had lower rates of breastfeeding initiation and maintenance for $\geq 12$ months (Table 1 ). Sex, age, living area, numbers of siblings, parental atopy history, and food allergy history were associated with the presence of $\mathrm{AR}$ in the univariate analyses $(P<0.05)$.

Table 2 shows the prevalence and OR ( $95 \% \mathrm{CI})$ for AR according to the MOD, duration of breastfeeding, and number of sib- 
Table 1. Selected characteristics of allergic rhinitis and non-allergic rhinitis in 1,374 children from the Allergic Rhinitis Cohort Study for kids (ARCO-kids), 2009-2011

\begin{tabular}{|c|c|c|c|}
\hline Variable & $\begin{array}{l}\text { Non-allergic rhinitis } \\
\quad(n=313)\end{array}$ & $\begin{array}{c}\text { Allergic rhinitis } \\
(n=1,061)\end{array}$ & $P$-value ${ }^{a)}$ \\
\hline \multicolumn{4}{|l|}{ Demographics } \\
\hline Age (yr) & $6.9 \pm 2.6$ & $8.1 \pm 2.6$ & $<0.001$ \\
\hline Sex & & & 0.003 \\
\hline Male & $193(61.7)$ & $748(70.5)$ & \\
\hline Female & $120(38.3)$ & $313(29.5)$ & \\
\hline Living area & & & 0.035 \\
\hline Rural & $33(11.5)$ & $78(7.6)$ & \\
\hline Urban & $264(88.5)$ & $947(92.4)$ & \\
\hline \multicolumn{4}{|l|}{ Maternal factor } \\
\hline Maternal age at marriage (yr) & $26.8 \pm 3.3$ & $27.0 \pm 3.2$ & 0.368 \\
\hline Maternal age at birth (yr) & $29.5 \pm 3.6$ & $29.9 \pm 3.7$ & 0.132 \\
\hline $\begin{array}{l}\text { Weight gain during } \\
\text { pregnancy }(\mathrm{kg})\end{array}$ & $13.8 \pm 5.9$ & $13.5 \pm 5.8$ & 0.557 \\
\hline \multicolumn{4}{|l|}{ Prenatal factor } \\
\hline Birth weight (kg) & $3.2 \pm 0.5$ & $3.3 \pm 0.4$ & 0.131 \\
\hline Gestational age (wk) & $39.2 \pm 1.8$ & $39.3 \pm 1.7$ & 0.309 \\
\hline Mode of delivery & & & 0.051 \\
\hline Vaginal delivery & $195(67.2)$ & $613(60.9)$ & \\
\hline Cesarean delivery & $95(32.8)$ & $393(39.1)$ & \\
\hline \multicolumn{4}{|l|}{ Postnatal factor } \\
\hline Breastfeeding initiation & & & 0.313 \\
\hline Yes & $231(73.8)$ & $763(71.9)$ & \\
\hline No & $82(26.1)$ & $293(28.1)$ & \\
\hline Breastfeeding duration (mo) & & & $<0.001$ \\
\hline$<6$ & $91(39.4)$ & $417(54.7)$ & \\
\hline $6-11$ & $50(21.6)$ & $162(21.2)$ & \\
\hline$\geq 12$ & $90(39.0)$ & $184(24.1)$ & \\
\hline Number of siblings & & & 0.048 \\
\hline 0 & $58(20.1)$ & $211(20.9)$ & \\
\hline 1 & $201(69.6)$ & $637(63.2)$ & \\
\hline$\geq 2$ & $30(10.4)$ & $160(15.9)$ & \\
\hline \multicolumn{4}{|l|}{ Allergy-related history } \\
\hline Parental atopy history & & & 0.011 \\
\hline No & $284(90.7)$ & $919(86.6)$ & \\
\hline Yes & $29(9.3)$ & $142(13.4)$ & \\
\hline Food allergy history ${ }^{b)}$ & & & 0.022 \\
\hline No & $259(87.4)$ & $850(81.6)$ & \\
\hline Yes & $37(12.6)$ & $192(18.4)$ & \\
\hline Pets at home $e^{b)}$ & & & 0.300 \\
\hline No & $270(90.3)$ & $911(88.0)$ & \\
\hline Yes & $19(9.7)$ & $125(12.0)$ & \\
\hline \multicolumn{4}{|l|}{ Parental smoking } \\
\hline At the time of pregnancy & & & 0.257 \\
\hline No & $52(24.3)$ & $222(28.4)$ & \\
\hline Yes & $162(75.7)$ & $561(71.6)$ & \\
\hline \multicolumn{2}{|c|}{ At the time of current enrollment } & & 0.201 \\
\hline No & $75(35.0)$ & $471(39.9)$ & \\
\hline Yes & $139(65.0)$ & $278(60.1)$ & \\
\hline
\end{tabular}

Values are presented as mean \pm standard deviation or number (\%). The total number of children does not equal to 1,374 because of missing data. a)To test the differences between the two groups (allergic rhinitis vs. nonallergic rhinitis), we used the Student $t$-test for continuous variables and the Pearson chi-square or Fisher exact test for categorical variables. ${ }^{\text {b) There }}$ was no statistically significant difference in each type of food allergy, each type of pets, and the number of pets at home between the two groups. lings. Compared with short-term breastfeeding ( $<6$ months), long-term breastfeeding ( $\geq 12$ months) was significantly associated with a lower prevalence of AR (OR, 0.53; 95\% CI, 0.37 to 0.74); this association remained statistically significant after accounting for age, sex, MOD, number of siblings, parental atopy history, and living area (aOR, 0.54; 95\% CI, 0.34 to 0.88 ). Compared with breastfeeding for $<6$ months, breastfeeding for 6-11 months was not statistically significantly related to the risk of AR (OR, 0.77; 95\% CI, 0.52 to 1.15; aOR, 0.80; 95\% CI, 0.57 to 1.14 ). Children born by cesarean delivery had an increased prevalence of AR compared with those born by vaginal delivery, but when this was added to the multivariable models, the association became less evident and was no longer statistically significant (OR, 1.30; 95\% CI, 0.98 to 1.72; aOR, 1.26; $95 \%$ CI, 0.93 to 1.66). There was no appreciable association between the number of siblings and the risk of AR in the stratified analysis.

Table 3 shows ORs for the combination of breastfeeding duration and MOD in AR and NAR. Compared with children born by cesarean delivery who were breastfed for $<6$ months, those born by vaginal delivery and breastfed for $\geq 12$ months showed resistance to the development of $\mathrm{AR}(\mathrm{OR}, 0.46 ; 95 \% \mathrm{CI}, 0.30$ to 0.73; aOR, 0.47 ; $95 \%$ CI, 0.30 to 0.73 ). Moreover, longer breastfeeding and vaginal delivery showed the lowest risk for AR.

\section{DISCUSSION}

The results from this large-population study indicate that longterm breastfeeding ( $\geq 12$ months) is strongly associated with a decreased risk of AR in Korean children. This is consistent with previous reports that breastfeeding is associated with a decreased risk of allergic diseases $[6,17,18]$. In a birth cohort study in Sweden, early exclusive breastfeeding for $\geq 4$ months was shown to reduce the risk of eczema and the onset of the allergic march at the age of four [13]. Another study in the United States showed that prolonged breastfeeding ( $\geq 4$ months) in AfricanAmerican subjects reduced the risk of AR at age 3 [12]. The protective mechanisms of breastfeeding against allergic disease are not well understood. However, several possible mechanisms have been proposed to explain these protective effects including, beneficial effects on lung development such as increased elasticity and efficiency of lung parenchyma [19], decreased exposure to exogenous antigens, and strengthened host defence mechanisms against infection through enhancement of the immature immune system [20,21]. Furthermore, it is thought that immunosuppressive factors in breast milk downregulate inflammation and prevent the development of allergies [22].

Despite these data, the effects of breastfeeding on allergic disease remain controversial. Several studies have suggested that prolonged breastfeeding increases the risk of developing allergic diseases $[11,15,23]$. One study found an increased risk for asth- 
Table 2. ORs for each factor in allergic rhinitis and non-allergic rhinitis in 1,374 children from the Allergic Rhinitis Cohort Study for kids (ARCOkids), 2009-2011

\begin{tabular}{|c|c|c|c|c|c|}
\hline Variable & Non-allergic rhinitis & Allergic rhinitis & OR $(95 \% \mathrm{Cl})^{\mathrm{a})}$ & OR $(95 \% \mathrm{Cl})^{\mathrm{b})}$ & $\left.\mathrm{OR}(95 \% \mathrm{Cl})^{\mathrm{c}}\right)$ \\
\hline \multicolumn{6}{|l|}{ Mode of delivery } \\
\hline Vaginal delivery & $195(67.2)$ & $613(60.9)$ & 1.00 & 1.00 & 1.00 \\
\hline Cesarean delivery & $95(32.8)$ & 393 (39.1) & $1.30(0.98-1.72)$ & $1.25(0.94-1.66)$ & $1.26(0.93-1.66)$ \\
\hline \multicolumn{6}{|c|}{ Breastfeeding duration (mo) } \\
\hline$<6$ & $91(39.4)$ & $417(54.7)$ & 1.00 & 1.00 & 1.00 \\
\hline $6-11$ & $50(21.6)$ & $162(21.2)$ & $0.77(0.52-1.15)$ & $0.78(0.52-1.16)$ & $0.80(0.57-1.14)$ \\
\hline$\geq 12$ & $90(39.0)$ & $184(24.1)$ & $0.53(0.37-0.74)$ & $0.50(0.35-0.72)$ & $0.54(0.34-0.88)$ \\
\hline \multicolumn{6}{|l|}{ Number of siblings } \\
\hline 0 & $58(20.1)$ & $211(20.9)$ & 1.00 & 1.00 & 1.00 \\
\hline 1 & 201 (69.6) & 637 (63.2) & $0.76(0.54-1.07)$ & $0.79(0.56-1.12)$ & $0.89(0.51-1.41)$ \\
\hline$\geq 2$ & $30(10.4)$ & $160(15.9)$ & $1.15(0.70-1.90)$ & $1.31(0.78-2.17)$ & $1.13(0.70-1.84)$ \\
\hline
\end{tabular}

Values are presented as number (\%). The total number of children does not equal to 1,374 because of missing data.

OR, odds ratio; $\mathrm{Cl}$, confidence interval.

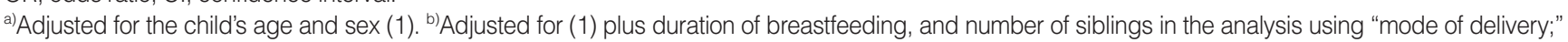
(1) plus mode of delivery, and number of siblings in the analysis using "breastfeeding duration;" (1) plus mode of delivery, and duration of breastfeeding in the analysis using "number of siblings" (2). ${ }^{c}$ Adjusted for (2) plus parental atopy history, and living area.

Table 3. ORs for the combination of breastfeeding duration and the mode of delivery in allergic rhinitis and non-allergic rhinitis in 1,374 children from the Allergic Rhinitis Cohort Study for kids (ARCO-kids), 2009-2011

\begin{tabular}{|c|c|c|c|c|c|}
\hline Variable & Non-allergic rhinitis & Allergic rhinitis & $\mathrm{OR}(95 \% \mathrm{Cl})^{\mathrm{a})}$ & OR $(95 \% \mathrm{Cl})^{\mathrm{b})}$ & OR $\left.(95 \% \mathrm{Cl})^{\mathrm{c}}\right)$ \\
\hline \multicolumn{6}{|l|}{ Combination of breastfeeding duration $(\mathrm{mo})^{\mathrm{d})}$ and mode of delivery } \\
\hline$<6 /$ Cesarean delivery & $32(13.9)$ & $159(20.9)$ & 1.00 & 1.00 & 1.00 \\
\hline$<6 /$ Naginal delivery & $59(25.5)$ & $257(33.7)$ & $0.89(0.55-1.43)$ & $0.92(0.57-1.49)$ & $0.90(0.52-1.56)$ \\
\hline 6-11/Cesarean delivery & $17(7.4)$ & $47(6.2)$ & $0.64(0.32-1.27)$ & $0.64(0.31-1.27)$ & $0.75(0.42-1.32)$ \\
\hline $6-11$ Naginal delivery & $33(14.3)$ & $115(15.1)$ & $0.76(0.44-1.31)$ & $0.68(0.42-1.41)$ & $0.62(0.38-1.03)$ \\
\hline$\geq 12 /$ Cesarean delivery & $19(8.2)$ & $71(9.3)$ & $0.57(0.26-1.37)$ & $0.65(0.45-1.64)$ & $0.64(0.37-1.08)$ \\
\hline$\geq 12$ Naginal delivery & $71(30.7)$ & $113(14.8)$ & $0.46(0.30-0.73)$ & $0.46(0.30-0.72)$ & $0.47(0.30-0.73)$ \\
\hline Higher risk (short breastfeeding and cesarean delivery) & $32(13.9)$ & $159(20.9)$ & 1.00 & 1.00 & 1.00 \\
\hline $\begin{array}{l}\text { Intermediate risk (vaginal delivery but short breastfeeding or } \\
\text { intermediate breastfeeding but cesarean delivery) }\end{array}$ & $76(32.9)$ & $304(39.9)$ & $0.76(0.51-1.13)$ & $0.76(0.51-1.13)$ & $0.80(0.51-1.24)$ \\
\hline $\begin{array}{l}\text { Lower risk (vaginal delivery but intermediate breastfeeding } \\
\text { or longer breastfeeding but cesarean delivery) }\end{array}$ & $52(22.5)$ & $186(24.4)$ & $0.65(0.43-0.99)$ & $0.65(0.42-0.99)$ & $0.63(0.41-0.97)$ \\
\hline Lowest risk (longer breastfeeding and vaginal delivery) & $71(30.7)$ & $113(14.8)$ & $0.46(0.30-0.73)$ & $0.46(0.30-0.72)$ & $0.47(0.30-0.73)$ \\
\hline
\end{tabular}

Values are presented as number (\%). The total number of children does not equal to 1,374 because of missing data.

$\mathrm{OR}$, odds ratio; $\mathrm{Cl}$, confidence interval.

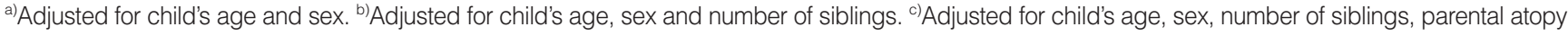
history and living area. ${ }^{\text {d) }}<6$ Months: shorter duration; 6-11 months: intermediate; $\geq 12$ months: longer duration.

ma and wheezing in breastfed children compared with that of children who were never breastfed by their asthmatic mothers [24]. The Osaka Maternal and Child Health Study did not find a statistically significant relationship between the duration of breastfeeding and the risk of wheezing or asthma in Japanese infants [14]. These discrepancies between the various studies can possibly be explained by differences in the study design, geographical location, ethnicity, and methodological factors [25-27].

In 2003, the World Health Organization (WHO) issued a revised global recommendation [28] that mothers should breastfeed their children exclusively for 6 months. Exclusive breastfeeding is the internationally preferred method of feeding babies during their first 6 months of life, and is recognized as being one of the most natural and best forms of preventive medicine [29]. For this reason, most studies $[6,12-15,18]$ on the duration of breastfeeding for prevention of allergic disease have focused on early, exclusive breastfeeding, and were designed with a relatively short duration of breastfeeding ( $<6$ months). There is lack of information about the effects of long-term breastfeeding in the prevention of allergic disease, despite the WHO recommendation that breastfeeding be continued up until the age of 2 years and even beyond. According to the Korean National Health and Nutrition Examination Survey (KNHANES V-2) [30], 39.5\% of the general Korean population continued breastfeeding up to 12 months. This figure is similar to the breastfeeding rate in the NAR group (39.0\%); however, the rate in the AR 
group was considerably lower $(24.1 \%)$ than in the NAR group, or the general population. In our study, long-term breastfeeding had a greater protective effect than a relatively short duration of breastfeeding ( $<6$ months and 6-11 months). This suggests that breastfeeding maintained for $\geq 12$ months is more effective in preventing AR in early life than breastfeeding initiation or only a short duration of breastfeeding.

Numerous studies have investigated the association between MOD and allergic disease, some of which have reached conflicting conclusions $[7,8,10,31,32]$. Our results demonstrated that cesarean delivery alone was associated with an increased risk of $\mathrm{AR}$; however, in the multivariable models, the association became less evident, and the statistical significance was lost. In the combined-effect analyses including breastfeeding duration and MOD, long-term breastfeeding combined with a vaginal delivery showed a strong protective effect against AR, compared with that of short-term breastfeeding with a cesarean delivery. Moreover, a vaginal delivery had a significant protective effect for children who had been breastfed for longer, compared to a cesarean delivery. These results mostly agree with those of several other epidemiological studies; in a Spanish cohort study, a cesarean delivery was shown to be a risk factor for an immunoglobulin E-mediated cow milk allergy in infants [8]. Another study also reported that a cesarean delivery was strongly associated with doctor-diagnosed asthma at 28 years of age [33]. The inverse correlation between a cesarean delivery and the risk of allergic disease is usually explained by delayed colonization of intestinal flora during the first few months of life. Infants born by cesarean delivery had no opportunity to be inoculated with bifidogenic microflora from their mother's vagina because they did not pass through the birth canal [34]. This lack of bifidogenic flora in the infant intestine is thought to affect the modulation of immune responses to allergens and the subsequent development of allergic disease [35,36].

Taken together, the results indicate that the MOD is a strong, independent environmental risk factor against the development of allergic disease. However, several studies have shown a close relationship between the MOD and breastfeeding behavior [37, 38]. Results from national Korean surveys have shown that a cesarean delivery significantly decreased the likelihood of breastfeeding initiation, and had a negative relationship with breastfeeding duration [37]. Therefore, MOD may act as a strong confounder when determining the environmental risk factors for developing allergic disease, especially when investigating breastfeeding behaviors. However, previous studies $[9,31,32]$ designed to investigate the correlation between the MOD and allergic disease did not investigate the possible effects of breastfeeding behavior, and were not adjusted for this factor, which may have influenced their results. For this reason, we analyzed the combined implications of breastfeeding duration and MOD to minimize any possible confounding effects between these two factors.
However, this study has some limitation. First, AR group was compared to NAR group. This is because the design of our prospective multicenter study required 5-year follow-up every 6 months. Thus, it is very difficult to enroll healthy participants in this cohort study. Secondly, this study focused on the maternal and perinatal environmental factors related to the development of AR. Therefore, well-known other risk factors at the time point of enrollment could be omitted in the analysis. Lastly, fetal and maternal condition could influence the selection of MOD such as cesarean section. The association between AR and MOD is partly explained by confounding effects of fetal growth restriction and pre-term birth.

Despite of these limitations, this study has distinguished points focusing on environmental factors in early life, especially breastfeeding duration and MOD, in contrast to previous studies on the risk factors for AR. Duration of breastfeeding and MOD were associated with childhood AR. Long-term breastfeeding in particular showed a greater protective effect against AR than a relatively short duration of breastfeeding, and this protective effect was strengthened if combined with a vaginal delivery.

\section{CONFLICT OF INTEREST}

No potential conflict of interest relevant to this article was reported.

\section{ACKNOWLEDGMENTS}

This study was supported by the Korea Centers for Disease Control and Prevention (grant number 2008-E00382-00), Seoul, Republic of Korea.

\section{ORCID}

$\begin{array}{ll}\text { Doo Hee Han } & \text { https://orcid.org/0000-0003-3367-1495 } \\ \text { Sue K. Park } & \text { https://orcid.org/0000-0001-5002-9707 } \\ \text { Chae-Seo Rhee } & \text { https://orcid.org/0000-0002-1361-8585 }\end{array}$

\section{AUTHOR CONTRIBUTIONS}

Conceptualization: CSR. Data curation: SA, JSK, DYK, SM, JSK, JSC, SWK, YHK, HJR, WSS, KSR, SWK, SSL, DWK, KSC, HJY. Formal analysis: SKP, SA. Funding acquisition: CSR. Methodology: SKP. Project administration: DHH. Visualization: JMS. Writing - original draft: DHH, JMS. Writing - review \& editing: CSR, SKP, DHH, DYK. 


\section{REFERENCES}

1. Guerra S, Sherrill DL, Martinez FD, Barbee RA. Rhinitis as an independent risk factor for adult-onset asthma. J Allergy Clin Immunol. 2002 Mar;109(3):419-25.

2. Plaschke PP, Janson C, Norrman E, Bjornsson E, Ellbjar S, Jarvholm B. Onset and remission of allergic rhinitis and asthma and the relationship with atopic sensitization and smoking. Am J Respir Crit Care Med. 2000 Sep;162(3 Pt 1):920-4.

3. Wang DY. Risk factors of allergic rhinitis: genetic or environmental? Ther Clin Risk Manag. 2005 Jun;1(2):115-23.

4. Castro-Rodriguez JA, Forno E, Rodriguez-Martinez CE, Celedon JC. Risk and protective factors for childhood asthma: what is the evidence? J Allergy Clin Immunol Pract. 2016 Nov-Dec;4(6):1111-22.

5. Bjorksten B, Kjellman NI. Perinatal environmental factors influencing the development of allergy. Clin Exp Allergy. 1990 Sep;20 Suppl 3:3-8.

6. Oddy WH, Peat JK, de Klerk NH. Maternal asthma, infant feeding, and the risk of asthma in childhood. J Allergy Clin Immunol. 2002 Jul;110(1):65-7.

7. Thavagnanam S, Fleming J, Bromley A, Shields MD, Cardwell CR.A meta-analysis of the association between Caesarean section and childhood asthma. Clin Exp Allergy. 2008 Apr;38(4):629-33.

8. Sanchez-Valverde F, Gil F, Martinez D, Fernandez B, Aznal E, Oscoz $\mathrm{M}$, et al. The impact of caesarean delivery and type of feeding on cow's milk allergy in infants and subsequent development of allergic march in childhood. Allergy. 2009 Jun;64(6):884-9.

9. Werner A, Ramlau-Hansen CH, Jeppesen SK, Thulstrup AM, Olsen J. Caesarean delivery and risk of developing asthma in the offspring. Acta Paediatr. 2007 Apr;96(4):595-6.

10. McKeeverTM, Lewis SA, Smith C, Hubbard R. Mode of delivery and risk of developing allergic disease. J Allergy Clin Immunol. 2002 May;109(5):800-2.

11. Wright AL, Holberg CJ,Taussig LM, Martinez FD. Factors influencing the relation of infant feeding to asthma and recurrent wheeze in childhood.Thorax. 2001 Mar;56(3):192-7.

12. Codispoti CD, Levin L, LeMasters GK, Ryan P, Reponen T, Villareal $\mathrm{M}$, et al. Breast-feeding, aeroallergen sensitization, and environmental exposures during infancy are determinants of childhood allergic rhinitis. J Allergy Clin Immunol. 2010 May;125(5):1054-60.

13. Kull I, Bohme M,Wahlgren CF, Nordvall L, Pershagen G, Wickman M. Breast-feeding reduces the risk for childhood eczema. J Allergy Clin Immunol. 2005 Sep;116(3):657-61.

14. Miyake Y,Tanaka K, Sasaki S, Kiyohara C, Ohya Y, Fukushima W, et al. Breastfeeding and atopic eczema in Japanese infants: The Osaka Maternal and Child Health Study. Pediatr Allergy Immunol. 2009 May;20(3):234-41.

15. Sears MR, Greene JM, Willan AR, Taylor DR, Flannery EM, Cowan $\mathrm{JO}$, et al. Long-term relation between breastfeeding and development of atopy and asthma in children and young adults: a longitudinal study. Lancet. 2002 Sep;360(9337):901-7.

16. Lee JE, Ahn JC, Han DH, Kim DY, Kim JW, Cho SH, et al.Variability of offending allergens of allergic rhinitis according to age: optimization of skin prick test allergens. Allergy Asthma Immunol Res. 2014 Jan;6(1):47-54.

17. Friedman NJ, Zeiger RS. The role of breast-feeding in the development of allergies and asthma. J Allergy Clin Immunol. 2005 Jun; 115(6):1238-48.
18. Gdalevich M, Mimouni D, David M, Mimouni M. Breast-feeding and the onset of atopic dermatitis in childhood: a systematic review and meta-analysis of prospective studies. J Am Acad Dermatol. 2001 Oct; 45(4):520-7.

19. Ogbuanu IU, Karmaus W, Arshad SH, Kurukulaaratchy RJ, Ewart S. Effect of breastfeeding duration on lung function at age 10 years: a prospective birth cohort study. Thorax. 2009 Jan;64(1):62-6.

20. Oddy WH.A review of the effects of breastfeeding on respiratory infections, atopy, and childhood asthma. J Asthma. 2004 Sep;41(6): 605-21.

21. OddyWH, Halonen M, Martinez FD, Lohman IC, Stern DA, KurziusSpencer M, et al.TGF-beta in human milk is associated with wheeze in infancy. J Allergy Clin Immunol. 2003 Oct;112(4):723-8.

22. Xanthou M. Immune protection of human milk. Biol Neonate. 1998; 74(2):121-33.

23. Oddy WH, Peat JK. Breastfeeding, asthma, and atopic disease: an epidemiological review of the literature. J Hum Lact. 2003 Aug;19(3): 250-61.

24. Wright AL, Holberg CJ, Taussig LM, Martinez F. Maternal asthma status alters relation of infant feeding to asthma in childhood. Adv Exp Med Biol. 2000;478:131-7.

25. Litonjua AA, Celedon JC, Hausmann J, Nikolov M, Sredl D, Ryan L, et al. Variation in total and specific IgE: effects of ethnicity and socioeconomic status. J Allergy Clin Immunol. 2005 Apr;115(4):751-7.

26. Hunninghake GM, Weiss ST, Celedon JC. Asthma in Hispanics. Am J Respir Crit Care Med. 2006 Jan;173(2):143-63.

27. Skoner DP. Allergic rhinitis: definition, epidemiology, pathophysiology, detection, and diagnosis. J Allergy Clin Immunol. 2001 Jul;108 (1 Suppl):S2-8.

28. World Health Organization; UNICEF. Global strategy for infant and young child feeding. Geneva:World Health Organization; 2003.

29. Kramer MS, Kakuma R. The optimal duration of exclusive breastfeeding: a systematic review. Geneva: World Health Organization; 2001.

30. Ministry of Health and Welfare, Korea Centers for Disease Control and Prevention. Korea Health Statistics 2011: Korea National Health and Nutrition Examination Survey (KNHANESV-2). Cheongju: Korea Centers for Disease Control and Prevention; 2012.

31. Juhn YJ, Weaver A, Katusic S, Yunginger J. Mode of delivery at birth and development of asthma: a population-based cohort study. J Allergy Clin Immunol. 2005 Sep;116(3):510-6.

32. Keski-Nisula L, Harju M, Jarvelin MR, Pekkanen J.Vacuum-assisted delivery is associated with late-onset asthma. Allergy. 2009 Oct; 64 (10):1530-8.

33. Xu B, Pekkanen J, Hartikainen AL, Jarvelin MR. Caesarean section and risk of asthma and allergy in adulthood. JAllergy Clin Immunol. 2001 Apr;107(4):732-3.

34. Host A, Halken S. Primary prevention of food allergy in infants who are at risk. Curr Opin Allergy Clin Immunol. 2005 Jun;5(3):255-9.

35. Schiffrin EJ, Blum S. Interactions between the microbiota and the intestinal mucosa. Eur J Clin Nutr. 2002 Aug;56 Suppl 3:S60-4.

36. Annesi-Maesano I, Moreau D, Strachan D. In utero and perinatal complications preceding asthma. Allergy. 2001 Jun;56(6):491-7.

37. Chung W, Kim H, Nam CM. Breast-feeding in South Korea: factors influencing its initiation and duration. Public Health Nutr. 2008 Mar;11(3):225-9.

38. Ever-Hadani P, Seidman DS, Manor O, Harlap S. Breast feeding in Israel: maternal factors associated with choice and duration. J Epidemiol Community Health. 1994 Jun;48(3):281-5. 